\title{
Study to improve an amphoteric sulfonate alkyl ester surfactant by mixing with nonionic surfactant to reduce brine-waxy oil interfacial tension and to increase oil recovery in sandstone reservoir: T-KS field, Indonesia
}

\author{
Taufan Marhaendrajana $^{1}\left[\right.$ (D) Rani Kurnia ${ }^{1} \cdot$ Dimas Irfana $^{3} \cdot$ Doddy Abdassah $^{1} \cdot$ Deana Wahyuningrum $^{2}$
}

Received: 22 January 2018 / Accepted: 10 June 2018 / Published online: 16 June 2018

(c) The Author(s) 2018

\begin{abstract}
Crude oil with a high wax content and high pour point can be very challenging when enhanced oil recovery by surfactant flooding is to be applied. High wax content in crude oil will lead to high intermolecular interaction because of the increasing cohesion forces. It causes interfacial (IFT) tension between oil and brine to be high. Hence, oil recovery is relatively low. This paper presents formulation of an amphoteric sulfonate alkyl ester (SAE) surfactant with a nonionic surfactant (ester group) to reduce oil-brine IFT in waxy oil of T-KS field, in Indonesia. The ion-dipole forces may occur between SAE surfactant and nonionic cosurfactant molecules. The forces cause sulfonate chain to be attracted to oil phase. The formulated surfactant produces low interfacial tension between brine and waxy oil of T-KS oil field. Its ability to displace remaining oil in the pore space was also tested using coreflood tests. These tests demonstrate considerably good incremental recovery.
\end{abstract}

Keywords Sulfonate alkyl ester $\cdot$ Waxy oil $\cdot$ Enhance oil recovery $\cdot$ Ion-dipole interaction

\section{Introduction}

The research of surfactant for enhanced oil recovery has been continuously developing. It has been long known surfactant ability to lower interfacial tension of oil-brine. Hence, it reduces capillary forces of oil-brine in the pores which results in increasing displacement efficiency and lowering residual oil saturation. Some other recognized mechanisms responsible for surfactant increasing oil recovery in the literatures are wettability alteration (Kremesec and Treiber 1976; Hirasaki et al. 2011), interfacial charge

Taufan Marhaendrajana

tmarhaendrajana@tm.itb.ac.id

1 Department of Petroleum Engineering, Faculty of Mining and Petroleum Engineering, Institut Teknologi Bandung, Jalan Ganesha No. 10, Bandung, Indonesia

2 Department of Chemistry, Faculty of Mathematics and Natural Sciences, Institut Teknologi Bandung, Jalan Ganesha No. 10, Bandung, Indonesia

3 Department of Petroleum Engineering, Faculty of Mineral Technology, Universitas Pembangunan Nasional "Veteran" Yogyakarta, Jalan SWK 104 (Lingkar Utara), Condongcatur, 55283 Yogyakarta, Indonesia
(Sharma and Shah 1989), interfacial viscosity (Berridge et al. 1968; Strassner 1968; Wasan and Mohan 1977) and middle-phase microemulsions (Gogarty and Tosch 1968; Gogarty 1977; Holm and Robertson 1981). A theoretical model was introduced by Huh (1979) to predict oil-water interfacial tension as a function of corresponding solubilization ratio of oil and water in the microemulsion-phase (middle-phase). As solubilization ratio of oil and water for specific surfactant is affected by water salinity, Salager et al. (1979) showed that optimum salinity can be established as a function of surfactant structure, alkane carbon number $(\mathrm{ACN})$, and alcohol type, concentration, and temperature. Recently in 2017, Torrealba and Johns presented a model that predicts interfacial tension and phase behavior for all Winsor types and overall compositions.

There have been many authors who presented and discussed sulfonate surfactant with various structures and some of them are internal olefin sulfonates mixed with alcoholalkoxy-sulfate (Barnes et al. 2010), methyl ester sulfonates from vegetables oil (Majidaie et al. 2012), alpha olefin sulfonates (Hosseini-Nasab et al. 2015), mixture of alcohol propoxy sulfates-internal olefin sulfonates-C15-16 chain length 
(Puerto et al. 2015) and sulfonate alkyl ester (Marhaendrajana et al. 2016).

Martiz et al. (2015) studied the synergism between ionic (sodium m, p-exylbenzenesulfonate and sodium m, p-octylbenzene sulfonate) and nonionic (lauryl alcohol polyoxyethylene ether) surfactants for producing low interfacial tension at oil-water interface. The study used mesoscopic Dissipative Particle Dynamic Simulations and laboratory experiment to predict and measure the interfacial tension, respectively. At optimum mixture ratio, they showed that addition of nonionic surfactant reduced interfacial tension of alkane/water. They suggested the main mechanism of nonionic surfactant is to produce a very wide interface and as consequence most of the lipophilic group of ionic surfactant are inside the interface, while their hydrophilic groups are on the side of the water phase. Nonetheless, study by Martiz used pure alkane and the interfacial tension was above $10 \mathrm{mN} / \mathrm{m}$, while most enhanced oil recovery purposes require interfacial tension of oil-water below $10^{-2} \mathrm{mN} / \mathrm{m}$.

Kremesec et al. (1988) studied mixtures of anionic crude oil sulfonate and nonionic ethoxylated alcohol surfactants and they observed through laboratory experiments that low IFT and good solubilization parameter could be achieved by optimizing the HLB of nonionic surfactant.

Marhaendrajana et al. (2017) showed that sulfonated alkyl ester (SAE) surfactant reduces the interfacial tensions of both heavy and light oil samples with water in a wide range of salinity with monovalent and divalent ions present. However, it was shown that optimum salinity is about 30,000 and 100,000 ppm for heavy oil and light oil samples, respectively. The oil samples have insignificant wax content.

It is the purpose of this paper to formulate the SAE surfactant to be used for T-KS oil sample with high wax content. At the same time, the formulation is needed to work for low brine salinity since in T-KS field, the brine salinity is as low as $2560 \mathrm{ppm}$. The SAE surfactant (Fig. 1) is an ester compound with a sulfonate group attached to the alkyl chains as a branch, such that this surfactant has two hydrophilic groups. By structure, SAE is an amphoteric surfactant with anion sulfonate and non-polar ester as hydrophilic heads. The formulation is conducted by

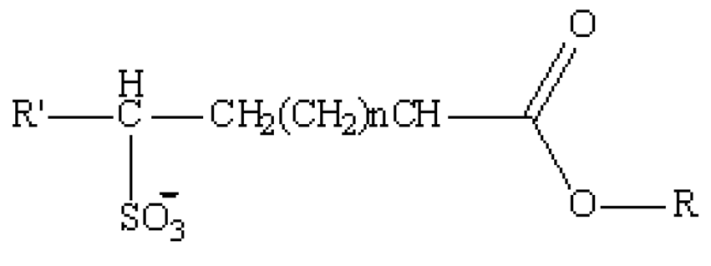

With $\mathrm{R}_{\mp} \mathrm{R}^{\prime}$

Fig. 1 Sulfonate alkyl ester (SAE) chemical structures (Marhaendrajana et al. 2016) mixing amphoteric SAE with nonionic (ester group) surfactants. This differentiates with previous authors who mixed anionic with nonionic surfactants (Kremesec et al. 1988; Martiz et al. 2015) or anionic with cationic surfactants (Li et al. 2016).

The goal of this study is to determine (i) whether mixture of amphoteric SAE and nonionic ester surfactants improve the IFT of low salinity brine and high wax content oil at T-KS field, and (ii) whether the blended surfactants perform reasonably good displacement to increase oil recovery.

\section{Materials and methods}

\section{Surfactants}

This study used mixtures of an amphoteric sulfonate alkyl ester (SAE) surfactant and a nonionic surfactant, FE-18, in various ratios. Both sulfonate alkyl ester (SAE) and the FE-18 surfactants were synthesized in Organic Synthesis and Bioorganic Chemistry Laboratory, Department of Chemistry-ITB.

The SAE surfactant has a sulfonate group and an ester group on the hydrophilic group. The sulfonated alkyl ester (SAE) surfactant has $40-45 \%$ yields and melting point above $300{ }^{\circ} \mathrm{C}$. The SAE surfactant has been characterized for the chemical structure using FTIR and LCMS. A typical FTIR spectrum of the SAE surfactant featured bands at wavenumbers of 3410.15-3448.72 (O-H alcohol), $2927\left(\mathrm{CH}_{2}\right.$, asymmetric), $1722.43(\mathrm{C}=\mathrm{O}$, ester), $1232.51(\mathrm{C}-\mathrm{O}-\mathrm{C}$, ester $)$, and $975.98-1141.86\left(\mathrm{~S}=\mathrm{O}\right.$, sulfonate) $\mathrm{cm}^{-1}$. And from the LCMS measurement, the SAE surfactant appears in chromatogram at retention time $3.6 \mathrm{~min}$ and the mass spectrum showed that the SAE surfactant has molecular weight (MW) higher than $500 \mathrm{~g} / \mathrm{mol}$.

The FE-18 surfactant is the liquid compound which resulted at the end of synthesis SAE surfactant, and about $40 \%$ of FE- 18 surfactant is produced from the end of the synthesis process. At the end of the synthesis process, both SAE and FE-18 surfactant are immiscible, which can be separated gradually. The FE-18 surfactant has $30-40 \%$ yields. The structure of FE-18 surfactant has been characterized using FTIR spectrophotometer and LCMS measurements. A typical FTIR spectrum of the FE-18 surfactant featured bands at wavenumbers of 3410.15-3448.72 (O-H alcohol), $2927\left(\mathrm{CH}_{2}\right.$, asymmetric), $1722.43(\mathrm{C}=\mathrm{O}$, ester $)$ and 1232.51 (C-O-C, ester) and 671.227-729.092 ( $\mathrm{C}=\mathrm{C}$ asymmetric stretch). And from the LCMS measurement, the FE-18 surfactant appears in chromatogram at retention time $23.2 \mathrm{~min}$ and the mass spectrum showed that the FE-18 surfactant has molecular weight (MW) higher than $650 \mathrm{~g} / \mathrm{mol}$. 


\section{Oil and brine samples}

The oil sample properties used in this study are as follows: wax content $36.09 \%$, resins $0.102 \%$ (Putra 2004), asphaltenes $0.13 \%$, pour point about $36-40{ }^{\circ} \mathrm{C}$, viscosity $7.9 \mathrm{cP}$, API gravity 40.08, total acid number $3.86 \mathrm{mg} / \mathrm{g} \mathrm{KOH}$ and EACN of 25.2.

The reservoir brine sample has salinity $2560 \mathrm{ppm}$, total dissolved solid $3430 \mathrm{ppm}$, density $0.9846 \mathrm{~g} / \mathrm{mL}$, pH 7.32, and concentration of calcium and magnesium ions, respectively, are 138 and $10.5 \mathrm{ppm}$.

\section{IFT and CMC measurements}

This measurement was conducted to determine the surfactant ability to lower the interfacial tension of oil-brine and to determine its critical micelle concentration (CMC) using spinning drop Tensiometer TX-500D at $63 \pm 0.5{ }^{\circ} \mathrm{C}$ (reservoir temperature) with $6000 \mathrm{rpm}$ of rotation for $30 \mathrm{~min}$. The IFT measurement of each concentration is measured twice that showed repeatability and consistent results.

\section{Coreflood tests}

These tests were conducted using a coreflooding apparatus as seen schematically in Fig. 2. The coreflooding tests were conducted to determine the incremental oil recovery by injection of formulated SAE surfactant. Berea core was used in this test. First the core was saturated by brine. Oil was then injected until displaced brine was no longer produced. The cumulative produced brine was set to be initial oil volume in the core sample. To let the fluids distributed uniformly, the treated core was aged for about $24 \mathrm{~h}$ at reservoir temperature.

Next stage, brine was injected with rate of $0.3 \mathrm{cc} / \mathrm{min}$ until there is no oil produced (this usually take $2-3 \mathrm{PV}$ ), then the surfactant injection was started with rate of $0.3 \mathrm{cc} / \mathrm{min}$ for $5 \mathrm{PV}$. This large PV injected surfactant is not normally done during implementation in the field, but our goal in this coreflooding test is to determine the ultimate incremental recovery (displacement efficiency) that could be obtained from the surfactant injection under study. This test was done for three Berea cores.

\section{Results and discussion}

\section{Pre-analysis of surfactants}

Griffin $(1949,1954)$ classified surfactants based on hydrophilic-lipophilic balance (HLB) and proposed a formula to compute HLB of ionic and nonionic surfactants. There is a correlation between chemical structure of surfactant and its physical properties (Fujimoto 1985). Swadesi et al. (2015) conducted laboratory tests of various surfactants for Tempino field, and showed that surfactant with HLB between 11 and 12 has low interfacial tension of oil-brine, which was performed at total brine salinity $15,540 \mathrm{ppm}$. However, different oil and brine compositions should have a different optimum range HLB value. Lower HLB value is suitable for low salinity brine or for high EACN oil, and vice versa. HLB of SAE and FE-18 surfactants are 11.9 and 12.8, respectively, shown by Table 1 . Nonetheless, HLB method does not take into account the effect of some formulation variables such as salinity, hardness, temperature, alkali, cosolvent type and concentration, and cosurfactant type and concentration.

Predicted optimum salinity for SAE surfactant may be computed by Solairaj's formula (2012). The formula is given in Eq. 1. This formula was based on Salager correlation (1979) which later generalized in term of hydrophilic-lipophilic deviation-HLD (Salager et al. 2000). It extended to include more variety of surfactants.

$$
\begin{aligned}
\log \left(S^{*}\right)= & a_{1} E_{0}+a_{2} N_{\mathrm{PO}}+a_{3} N_{\mathrm{EO}}+a_{4}\left(T-T_{\mathrm{ref}}\right) \\
& +a_{5} N_{\mathrm{c}}+a_{6} N_{\mathrm{c}} * N_{\mathrm{PO}}+C
\end{aligned}
$$

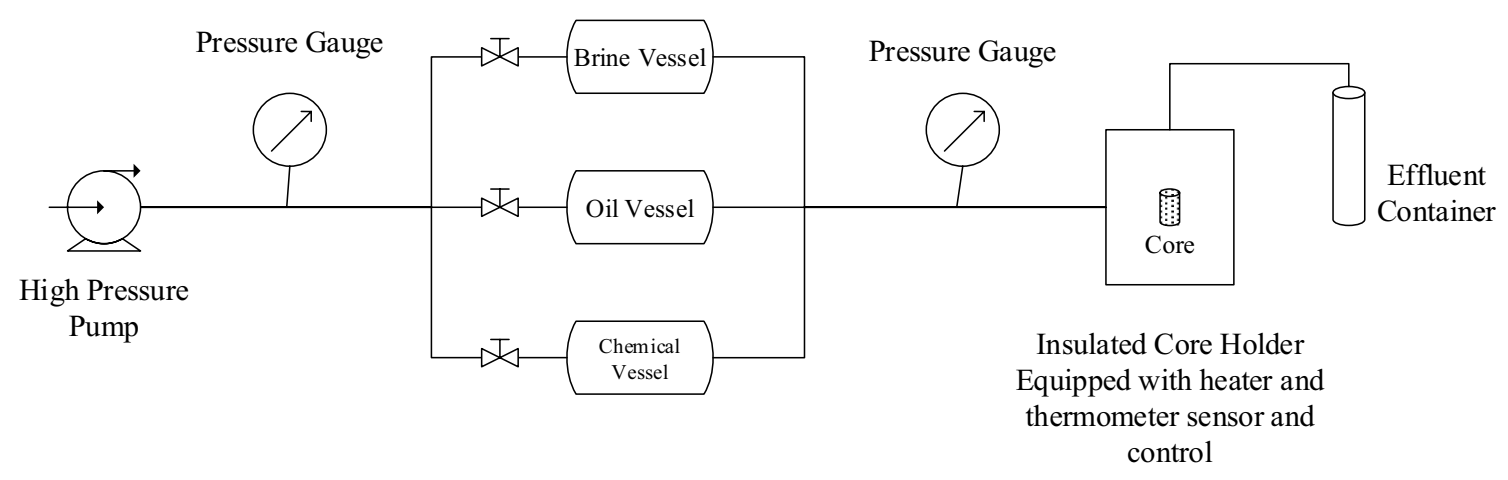

Fig. 2 Coreflooding apparatus scheme 
Table 1 Surfactant characteristics

\begin{tabular}{lccccccc}
\hline Surfactant & $\mathrm{MW}_{\mathrm{h}}$ & $\mathrm{MW}$ & $\mathrm{N}_{\mathrm{PO}}$ & $\mathrm{N}_{\mathrm{EO}}$ & $\mathrm{Nc}$ & $\begin{array}{l}\text { HLB (Griffin's } \\
\text { Formula) }\end{array}$ & $\begin{array}{l}\text { Optimum Salinity } \\
\text { (Solairaj's For- } \\
\text { mula) }\end{array}$ \\
\hline SAE & 349 & 587 & - & 5.5 & 18 & 11.9 & 109,602 \\
FE-18 & 424 & 661 & - & 9.0 & 18 & 12.8 & 77,423 \\
\hline
\end{tabular}

where $a_{1}=0.025458, a_{2}=-0.15103, a_{3}=-0.04285$, $a_{4}=0.002729, a_{5}=-0.07165$, and $a_{6}=0.004026$ are regression coefficients and $C=5.808061$ is the intercept, $N_{\mathrm{c}}$ is mole average weighted carbon number (in the hydrophobe) of surfactant mixture, $E_{\mathrm{o}}$ is the equivalent alkane carbon number of the oil, $N_{\mathrm{PO}}$ is mole average weighted propylene oxide number in the surfactant mixture, $N_{\mathrm{EO}}$ is mole average weighted ethylene oxide number in the surfactant mixture, $T$ is temperature of interest $\left({ }^{\circ} \mathrm{C}\right), T_{\text {ref }}$ is reference temperature $\left(21^{\circ} \mathrm{C}\right)$ and $S^{*}$ is optimum salinity.

For SAE surfactant, the optimum salinity would be about 109,602 ppm while the FE-18 has optimum salinity of 77,423 ppm. Implementation of high-salinity surfactant injection is considered impractical and disadvantageous in T-KS field that has low salinity. Hence, it is attempted to mix SAE surfactant with nonionic FE-18 surfactant. Although, by prediction in Table 1, individually, both surfactants have high optimum salinity, ion-dipole force mechanism may occur between anion sulfonate of SAE and dipole moment $\mathrm{C}=\mathrm{O}$ of lipophilic FE-18. Therefore, the HLB of SAE surfactant is expected to become lower and increase the interaction to oleic phase. This mechanism is expected to provide similar effect as increasing the salinity of brine which reduces the interaction of hydrophilic head of surfactant with water phase. Optimum ratio of the mixture was sensitized by measuring IFT oil-brine.

\section{Ion-dipole forces between SAE and FE-18}

The arrangement of SAE surfactant at oil-water interface is shown by Fig. 3a. At low salinity of brine, the sulfonate group is more freely to interact with water molecules because of less competition with salt ions. This arrangement led to hydrophobic chains that interact with the oil to be reduced in number, because some of the carbon chains are in a horizontal position on the interface of oil and water.

An ion-dipole force is an attractive force that results from the electrostatic attraction between an ion and a neutral molecule that has a dipole (Israelachvili 2011). A negative ion (anion) attracts the partially positive end of a neutral polar molecule. This phenomenon occurs when the SAE surfactant was blended with FE-18 surfactant, the SAE surfactant provides a pair of free electron as a negative charge at the sulfonate group and the FE-18 surfactant provides a neutral molecule that has a dipole at the carbonyl group (Fig. 3b). The initial SAE structure (Fig. 3a) has HLB value of 11.9.
Fig. 3 Illustration a the arrangement of SAE molecule in the oil-water interface and $\mathbf{b}$ the arrangement of SAE blended with FE-18 molecules in the oil-water interface

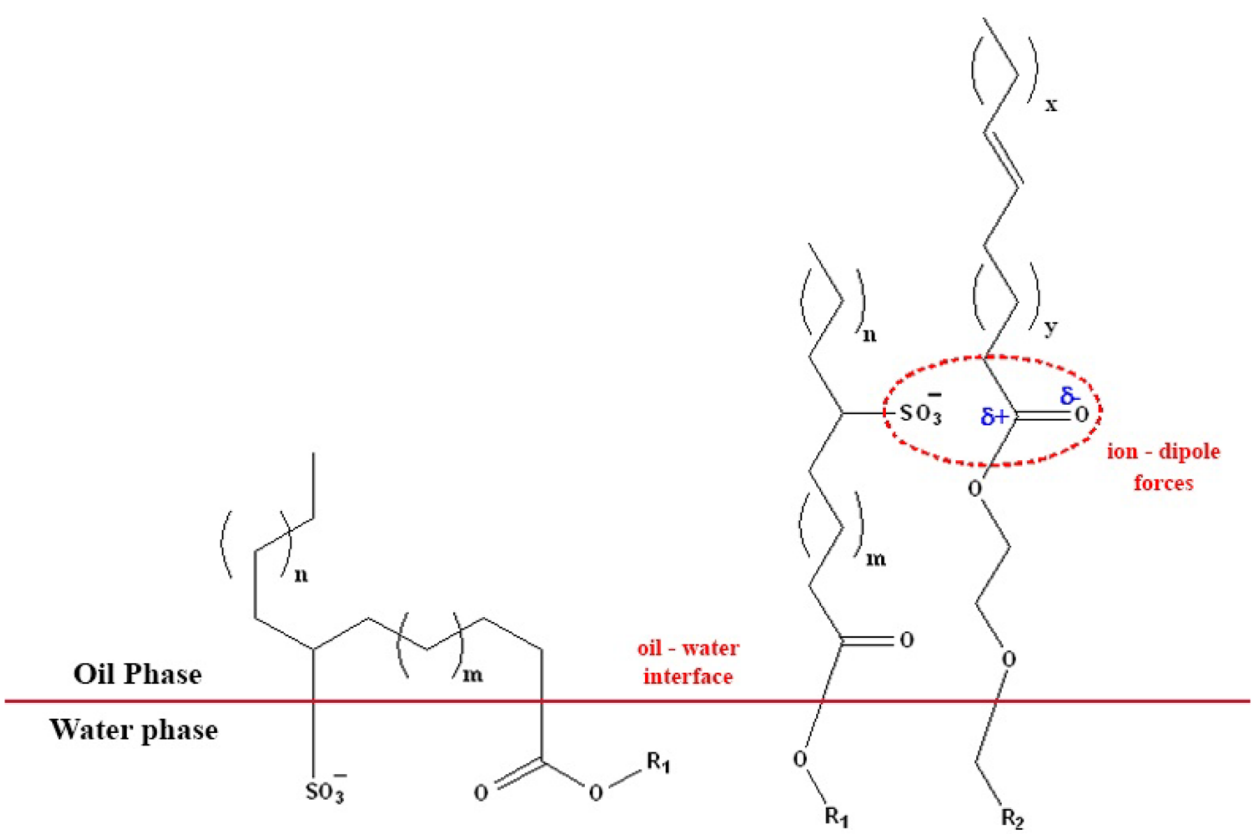

(a) (b)

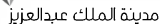
KACST 
When nonionic FE-18 is present and ion-dipole force exists as in Fig. 3b, the HLB of surfactant SAE reduces to 9.2.

\section{IFT and CMC measurements}

Mixture of SAE and FE-18 surfactants were done at ratio of $1: 1,2: 1$ and $1: 2$. The HLB of mixtures were computed using the following equation (ICI 1992; Torres et al. 2004).

$\mathrm{HLB}_{\text {mixture }}=\left(\mathrm{HLB}_{A}\right)\left(X_{A}\right)+\left(\mathrm{HLB}_{B}\right)\left(X_{B}\right)$

where $X_{A}$, and $X_{B}$ are the weight fraction of every surfactant present in the mixture. The calculation of HLB for each ratio of mixture is given in Table 2; SAE-01A has lower HLB followed by SAE-01B and SAE-01C. It indicates that hydrophilic head of SAE has least interaction to water phase among the three mixtures.

There is a positive correlation between HLB of surfactant mixtures and the measurement of IFT oil/water. At lower HLB, 1:1 ratio of SAE and FE-18 gives lower interfacial tension at oil-water interface. The main effect of nonionic surfactant tends to reduce the interaction of hydrophilic head to water phase due to the present of ion-dipole force between anion sulfonate and dipole $\mathrm{C}=\mathrm{O}$. The IFT values for various concentrations were plotted for the individual surfactant SAE and FE-18, and the mixtures at 1:1 ratio. It is shown in Fig. 4. Note that the CMC value for surfactant mixture (SAE $01 \mathrm{~A})$ is at $2 \% \mathrm{w} / \mathrm{w}$.

\section{Coreflooding tests}

Displacement tests by coreflooding were conducted to three Berea cores, namely B3, B6 and B15. Oil and Brine were taken from T-KS field. The tests were run at reservoir temperature, but the pressure was set at laboratory condition. The oil used in this test was then considered dead oil. Brine permeability was measured as $2,18.5$ and $28.5 \mathrm{mD}$, respectively, for core B3, B6, and B15. Surfactant mixture used was SAE 01A (1:1 ratio between SAE and FE-18) with 2\% concentration.

The coreflooding tests results are summarized in Table 3. Oil recovery during water injection for the cores are considerably small (less than 15\%), it is likely due to oil with high wax content. Waxy oil contains a very large hydrophobic molecules and there exists a high cohesion force between oil molecules due to the presence of high wax components. It causes high interfacial tension between oil and brine. Other factor could be due to low permeability. These result in a low waterflood recovery or high residual oil saturation after waterflood. The tests, in general, showed that injection of the selected surfactant mixture gives incremental oil recovery of the test cores up to $43.3 \%$ OOIP. Since the surfactant injection in these tests were conducted for $5 \mathrm{PV}$, for field implementation though, it needs to be optimized further for slug volume to decide if it is cost effective.

Test on core B3 (Fig. 5) shows that after approximately 2.3 PV water injection, $7.5 \%$ of original oil in place (OOIP)
Table 2 HLB value and IFT oil/water of various mixtures between SAE and FE-18 surfactants

\begin{tabular}{|c|c|c|c|c|}
\hline \multirow[t]{2}{*}{ Formulation code } & \multicolumn{2}{|c|}{ Weight fraction (\%) } & \multirow[t]{2}{*}{$\mathrm{HLB}_{\text {mixture }}$} & \multirow{2}{*}{$\begin{array}{l}\text { IFT at } 2 \% \mathrm{w} / \mathrm{w} \text { concentra- } \\
\text { tion of surfactant mixtures } \\
(\mathrm{mN} / \mathrm{m})\end{array}$} \\
\hline & SAE & FE-18 & & \\
\hline SAE-01A & 50 & 50 & 11.0 & 0.00259 \\
\hline SAE-01B & 66.7 & 33.3 & 11.3 & 0.11 \\
\hline SAE-01C & 33.3 & 66.7 & 11.6 & 0.369 \\
\hline
\end{tabular}

Fig. $4 \mathrm{CMC}$ measurement result of formulated SAE (SAE-01A) compared to SAE and FE-18 surfactants

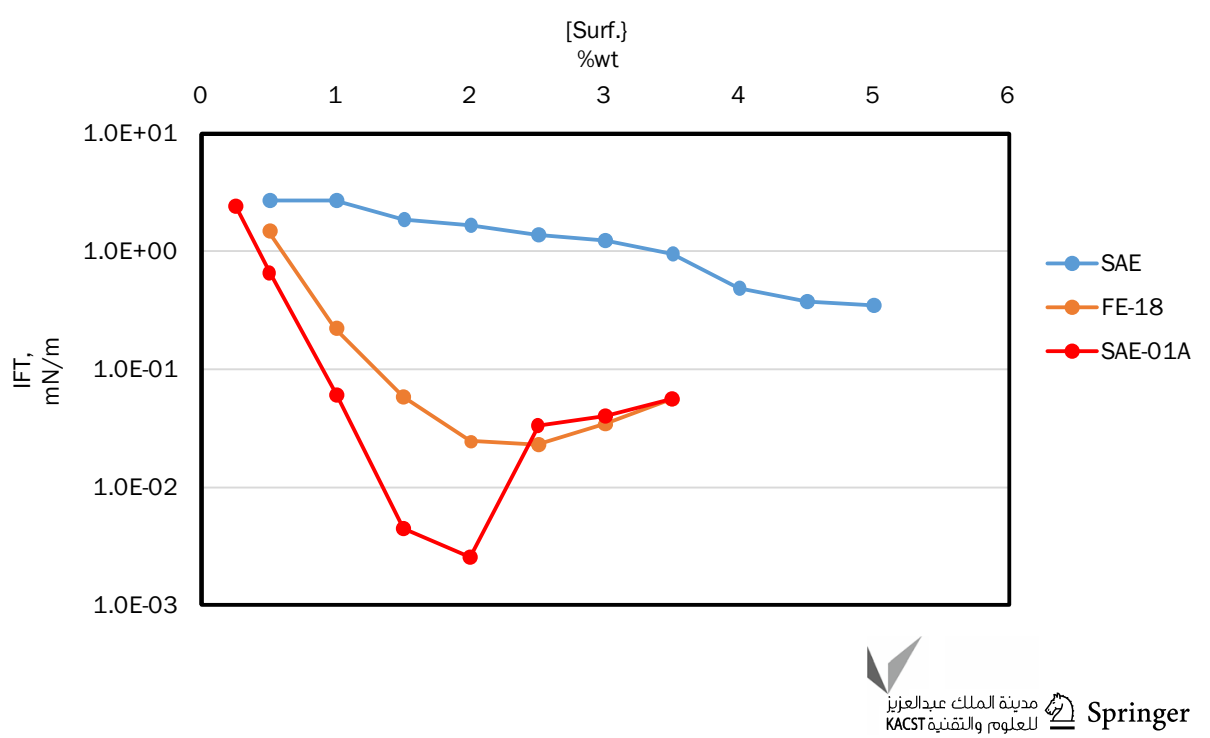


Table 3 Oil recovery of SAE-01A surfactant mixture

\begin{tabular}{llllllll}
\hline Core code & Core size $(\mathrm{LxD})(\mathrm{cm})$ & Porosity $(\%)$ & $\begin{array}{l}\text { Liquid (brine) } \\
\text { permeability } \\
(\mathrm{mD})\end{array}$ & $\begin{array}{l}\text { Initial oil } \\
\text { saturation } \\
(\%)\end{array}$ & $\begin{array}{l}\text { Oil recovered by } \\
\text { waterflood }(\% \\
\text { OOIP) }\end{array}$ & $\begin{array}{l}\text { Cumulative oil } \\
\text { recovered }(\% \\
\text { OOIP) }\end{array}$ & $\begin{array}{l}\text { Incremental oil } \\
\text { recovered }(\% \\
\text { OOIP) }\end{array}$ \\
\hline B3 & $2.99 \times 2.58$ & 19.48 & 1.92 & 65.65 & 7.5 & 25 & 17.5 \\
B6 & $3.27 \times 2.57$ & 20.16 & 18.5 & 58.27 & 12.5 & 42.5 & 30.0 \\
B15 & $3.23 \times 2.57$ & 18 & 28.5 & 49.73 & 11.7 & 55 & 43.3 \\
\hline
\end{tabular}

Fig. 5 Coreflooding test performance at core B3

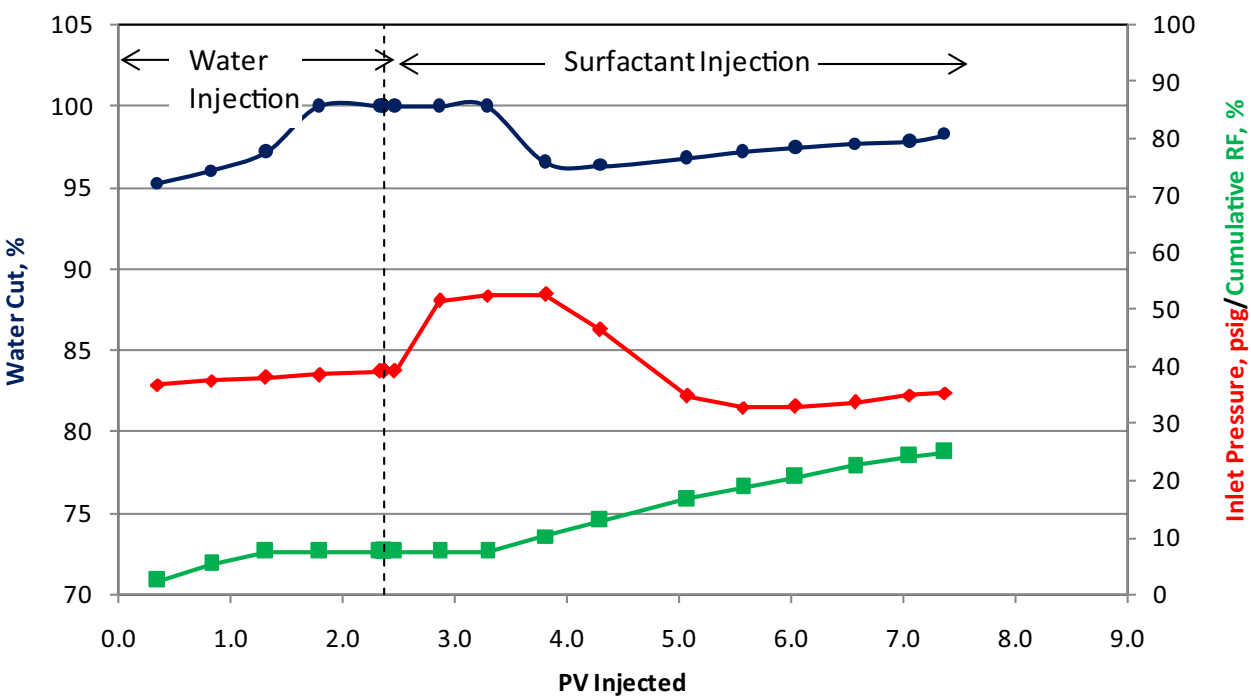

Test on core B15 (Fig. 7) shows that after approximately 3.2 PV water injection, $11.7 \%$ of original oil in place (OOIP) was recovered; thereafter, $5 \mathrm{PV}$ of surfactant injection yielded 55\% cumulative oil recovery. The incremental oil recovery was about $43.3 \%$. During water injection, pressure was relatively stable similarly as it was observed similarly in the two previous tests. As oil bank was formed and was mobilized, the pressure increased and oil production also increased (as well as water cut was decreasing). The pressure increased from 38 to $57 \mathrm{psi}$. After about 4.5 PV surfactant was injected, water cut increased and it suggested that continuing surfactant injection was no longer effective.

The three coreflooding tests showed incremental recovery from about $17-43 \%$ incremental recovery by continuous surfactant injection; however, it required an inefficient large number of about $5 \mathrm{PV}$ of $2 \%$ surfactant concentration to be applicable for field relevance. Small surfactant slug followed by polymer slug and chasing water was tested in the laboratory. Polymer was meant to provide better volumetric sweep efficiency to improve oil recovery with less volume of chemical injected. After water injection of a saturated berea core with oil and brine until reaching approximately residual oil saturation, the scenario was to inject with 0.5 PV surfactant SAE-01A followed by $1 \mathrm{PV}$ polymer slug and chased by water injection. Polymer viscosity was about 15 from 45 psi to 70 psi. 
Fig. 6 Coreflooding test performance at core B6
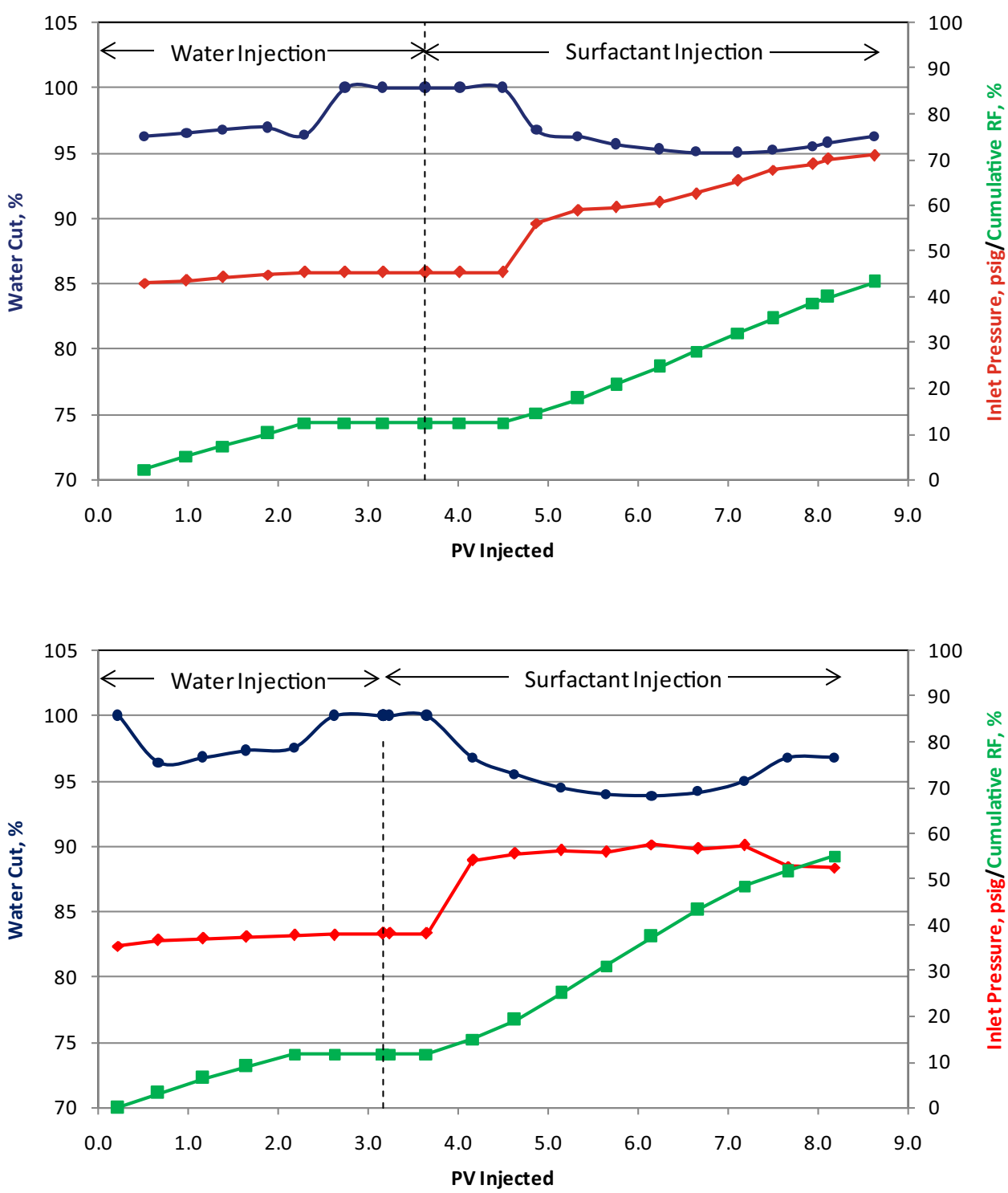

Fig. 7 Coreflooding test performance at core B15 cp (2000 ppm concentration of polymer) at reservoir temperature to achieved optimum mobility ratio. Core properties were dimension $3.285 \mathrm{~cm}$ of length $\times 2.54 \mathrm{~cm}$ of diameter, porosity $17.41 \%$, brine permeability $7 \mathrm{mD}$, and initial oil saturation $62.66 \%$. Coreflooding result is shown in Fig. 8.

At approximately 3.2 PV water injection, $16 \%$ of original oil in place (OOIP) was recovered, which approximately leaves residual oil in the core; thereafter, $0.5 \mathrm{PV}$ of surfactant injection and $1 \mathrm{PV}$ of polymer yielded $37 \%$ cumulative oil recovery. The incremental oil recovery was about $21 \%$. Coreflood was completed by injecting chasing water which gave additional incremental oil recovery of $7 \%$. Total incremental oil recovery from this injection scenario was $28 \%$. Compared to $5 \mathrm{PV}$ continuous surfactant flooding, the scenario of combining $0.5 \mathrm{PV}$ surfactant and $1 \mathrm{PV}$ polymer injection presented much more relevant case for field application.

\section{Conclusion}

HLB value by Griffin is useful as pre-design tool to obtain suitable surfactant to reduce IFT of oil-brine. The amphoteric SAE surfactant performance can be improved by the addition of nonionic FE-18 surfactant for reducing the interfacial tension of waxy oil and brine. It is possible mainly due to the surfactant arrangement at the interface of oil and brine. The SAE surfactant provides a pair of free electron as a negative charge at the sulfonate group and the FE-18 surfactant provides a neutral molecule that has a dipole at the carbonyl group. This ion-dipole force reduces the interaction of sulfonate compound to water phase.

Ratio of 1:1 w/w concentration between SAE and FE-18 surfactants (named as SAE-01A) was determined to be best combination mixture. This surfactant mixture reduces 
Fig. 8 Coreflooding test performance using scenario surfactant/polymer injection followed by chasing water

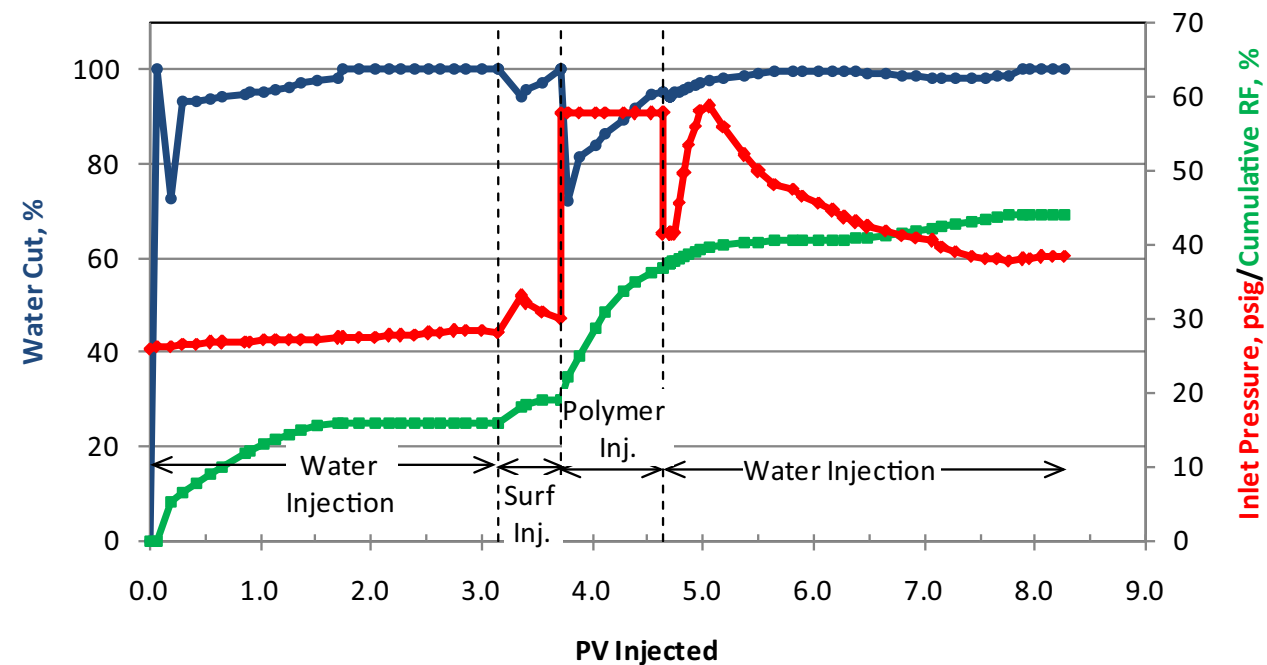

IFT between brine and waxy oil, and it also increases oil recovery. The coreflooding tests resulted in incremental oil recovery by surfactant flooding between 17.5 and $43.4 \%$ for the tested cores. For field relevance, the injection scenario was improved by injecting combination of $0.5 \mathrm{PV}$ surfactant slug and $1 \mathrm{PV}$ polymer slug followed by chasing water. The scenario provided more efficient chemical volume, and resulted in total incremental oil recovery $28 \%$.

Acknowledgements This research was funded by "Penelitian Unggulan Perguruan Tinggi" Kementrian Riset, Teknologi dan Pendidikan Tinggi (Ministry of Research, Technology and Higher Education of the Republic of Indonesia).

Open Access This article is distributed under the terms of the Creative Commons Attribution 4.0 International License (http://creativeco mmons.org/licenses/by/4.0/), which permits unrestricted use, distribution, and reproduction in any medium, provided you give appropriate credit to the original author(s) and the source, provide a link to the Creative Commons license, and indicate if changes were made.

\section{References}

Barnes JR, Dirkzwager H, Smit JR, Smit JP, On A, Navarrete RC, Ellison B, Buijse MA (2010) Application of internal olefin sulfonates and other surfactants to EOR. Part 1: structure-performance relationship for selection at different reservoir conditions. SPE 129766. In: Proceeding of SPE improved oil recovery symposium, Tulsa, Oklahoma: 24-28 April

Berridge SA, Thew MT, Loriston-Clarke AG (1968) The formation and stability of emulsions of water in crude petroleum and similar stoks. J Inst Pet 54(539):333

Fujimoto T (1985) New introduction to surface active agents. Sanyo Chemical Industries, Ltd, Kyoto

Gogarty WB (1977) Oil recovery with surfactants: history and current appraisal. In: Shah DO, Schechter RS (eds) Improved oil recovery by surfactant and polymer flooding. Academic Press, New York, pp 27-54
Gogarty WB, Tosch WC (1968) Miscible type water flooding: oil recovery with miscellar solutions. J Petrol Technol 20(12):1407-1414

Griffin WC (1949) Classification of surface active agents by HLB. J Soc Cosmet Chem 1: 311

Griffin WC (1954) Calculation of HLB values for nonionic surfactants. J Soc Cosmet Chem 5:259

Hirasaki GJ, Miller CA, Puerto M (2011) Recent advances in surfactant EOR. SPE J 16:889-907

Holm LW, Robertson SD (1981) Improved miscellar/polymer flooding with pH chemicals. J Pet Technol 33(1):161-172

Hosseini-Nasab SM, Zitha PL, Mirhaj SA, Simjoo M (2015) A new chemical enhanced oil recovery method. Soc Pet Eng. https://doi. org/10.2118/173732-MS

Huh C (1979) Interfacial tensions and solubilizing ability of a microemulsion phase that coexists with oil and brine. J Colloid Interface Sci 71(2):408-426

ICI (1992) The HLB system. A time saving guide to emulsifier selection. Wilmington, Delaware

Israelachvili JN (2011) Intermolecular and surface forces, 3rd edn. Elsevier Inc., San Diego

Kremesec VJ, Treiber LE (1976) Effect of system wettability on oil displacement by miscellar flooding. SPE 6001. In: Proceeding of 51st annual fall meeting, Society of Petroleum Engineers of AIME, New Orleans, La: October 3-6

Kremesec VJ, Raterman KT, Taggar DL (1988) Laboratory evaluation of a crude-oil-sulfonate/nonionic cosurfactant miscellar fluid. SPE Reservoir Eval 3: 801-808

Li Y, Zang W, Kong B, Puerto M, Bao X, Sha O, Shen Z, Yang Y, Gu S, Miller C, Hirasaki GJ (2016) Mixtures of anionic/cationic surfactants: a new approach for enhanced oil recovery in low salinity, high temperature sandstone reservoir. SPE J 21: 1-14

Majidaie S, Mushtaq M, Tan IM, Demiral B, Lee SY (2012) Nonpetrochemical surfactant for enhanced oil recovery. SPE 153493

Marhaendrajana T, Kurnia R, Wahyuningrum D, Fauzi I (2016) A novel sulfonated alkyl ester surfactant to reduce oil-water interfacial tensions in wide range salinity with monovalent and divalent ions. Mod Appl Sci (December) 10. https://doi.org/10.5539/mas. v10n1p93

Marhaendrajana T, Wahyuningrum D, Kurnia R, Buhari A (2017). Indonesia Patent No. 2017/04981

Martiz A, Samaniegi S, Aray Y (2015) Synergism between ionic and nonionic surfactants for producing low interfacial tension at oilwater interface. SPE 177211. In: SPE Latin American Caribbean 
petroleum engineering conference, Quito, Ecuador: November $18-20$

Puerto CM, Hirasaki GJ, Miller CA, Reznik C, Dubey S, Barnes JR, Kuijk SV (2015) Effects of hardness and cosurfactant on phase behavior of alcohol-free alkyl propoxylated sulfate systems. Soc Pet Eng. https://doi.org/10.2118/169096-MS

Putra SA (2004) Transportation of high pour point oil through long hilly terrain pipe line, a case study in Kalimantan Indonesia. https ://doi.org/10.2118/86929-MS

Salager JL, Morgan JC, Schechter RS, Wade WH, Vazquez E (1979) Optimum formulation of surfactant/water/oil/systems for minimum interfacial tension or phase behavior. Soc Pet Eng J: 107-115

Salager JL, Marquez N, Graciaa A, Lachaise J (2000) Partitioning of ethoxylated octylphenol surfactants in microemulsion-oil-water systems: influence of temperature and relation between partitioning coefficient and physicochemical formulation. Langmuir 16:5534-5539

Sharma MK, Shah DO (1989) Use of surfactants in oil recovery. In: Donaldson EC, Chilingarian GV (eds) Enhanced oil recovery II-processes and operation. Elsevier, Amsterdam, pp 255-315

Solairaj S, Britton C, Lu J, Kim DH, Weerasooriya U, Pope GA (2012) New correlation to predict the optimum surfactant structure for EOR. SPE improved oil recovery symposium, Tulsa, Oklahoma, USA, 14-18 April
Strassner JE (1968) Effect of $\mathrm{pH}$ on interfacial films and stability of crude oil - water emulsions. J Pet Technol 20(3):303-312

Swadesi B, Marhaendrajana T, Siregar S, Mucharam L (2015) The Effect of surfactant characteristics on ift to improve oil recovery in tempino light oil field indonesia. J Eng Technol 47(3):250-265. https://doi.org/10.5614/j.eng.technol.sci.2015.47.3.2

Torrealba VA, Johns RT (2017) Coupled interfacial tension and phase behavior model on micellar curvatures. Langmuir 33:1360413614. https://doi.org/10.1021/acs.langmuir.7b03372

Torres LG, Rojas N, Iturbe R (2004) Use of two-surfactants mixtures to get specific hlb values for assisted tph-diesel biodegradation. $\mathrm{J}$ Environ Sci 16(6):950-956

Wasan DT, Mohan V (1977) Interfacial rheological properties of fluid interfaces containing surfactants. In: Shah DO, Schechter RS (eds) Improved oil recovery by surfactant and polymer flooding. Academic Press, New York, pp 161-204

Publisher's Note Springer Nature remains neutral with regard to jurisdictional claims in published maps and institutional affiliations. 